\title{
A metrological inspection method using micro-CT for the analysis of drilled holes in CFRP and titanium stacks
}

\author{
Nadia Kourra $^{1} \cdot$ Jason M. Warnett $^{1} \cdot$ Alex Attridge $^{1} \cdot$ Aishah Dahnel $^{1}$. \\ Helen Ascroft ${ }^{1}$ • Stuart Barnes ${ }^{1} \cdot$ Mark A. Williams ${ }^{1}$
}

Received: 4 December 2015 / Accepted: 27 March 2016 / Published online: 14 May 2016

(c) The Author(s) 2016. This article is published with open access at Springerlink.com

\begin{abstract}
This paper demonstrates a novel method that combines X-ray computed tomography (CT) and image processing for investigating two materials with significantly different densities. CT is increasingly used in industrial applications of inspecting materials and defects. The limitations of the system and data reconstruction are continuously researched so as to improve the quality of the results. One of the most common issues in CT is beam hardening, frequently experienced in multi-material scanning. The materials examined to demonstrate the method are carbon fibre reinforced polymers (CFRP) and titanium alloy Ti6Al4V, often used in combination in industry to optimise the weight to strength ratio. The assembly of the materials is usually achieved by bolting and riveting, which requires drilling through the two materials together. The machining of these materials is difficult due to their higher specific properties and as a result tool wear is always an issue. CFRPs properties depend on the nature, orientation and bond of the fibres and as a result drilling affects their service life. The results of the method ensure the quality of the drilled holes by measuring the variation of the maximum diameter, circularity, positioning of the hole and an examining the entrance delamination and exit burrs by image processing.
\end{abstract}

Keywords Metrology · Computed tomography · Image processing · CFRP - Ti6A14V · Drilling - Non-destructive evaluation $\cdot$ Non- contact inspection

Nadia Kourra

N.Kourra@warwick.ac.uk

1 IMC, WMG, The University of Warwick, Coventry, CV4 7AL, UK

\section{Introduction}

X-ray computed tomography (CT) utilises a series of radiographs that are reconstructed into a 3D model that provides data of the outer surface and structure of the scanned specimen as well as the inner structure and any potential defects. The pixels of the radiographs have different grey values based on the amount of radiation reaching the detector after penetrating the scanned object (Fig. 1). The reconstruction of numerous radiographs collected from a $360^{\circ}$ rotation of the part with filtered back projection (FBP) converts the 2D pixels to 3D voxels that digitally rebuild the part. The voxels represent the entire volume rather than an externally observable area and can be exported for analysis. Variation in grey values within the $3 \mathrm{D}$ volume can demonstrate differences of density, the existence of either material or background or air and provide information of a defect such as porosity or cracks [1-5].

CT data is affected by many different variables that can influence its quality such as beam hardening that causes linear shadowing around the 3D reconstruction of the part or produces different grey values in homogeneous materials. This issue is caused by the nature of the polychromatic $x-$ ray beam spectrum and the attenuation of the radiation by the part. Polychromatic radiation includes a spectrum of different radiations up to the desirable radiation energy. The lower energy radiation is absorbed by the more dense materials, and it does not reach the detector while the higher energy radiation is able to penetrate the specimen. The normalisation of the data in the reconstruction process causes the creation of this phantoms, and it is a common issue in high energy scans and in multi-material scans [1].

The applications of CT can be separated into nondestructive evaluations and metrological investigations. As a non-destructive evaluation technique, the data does not 


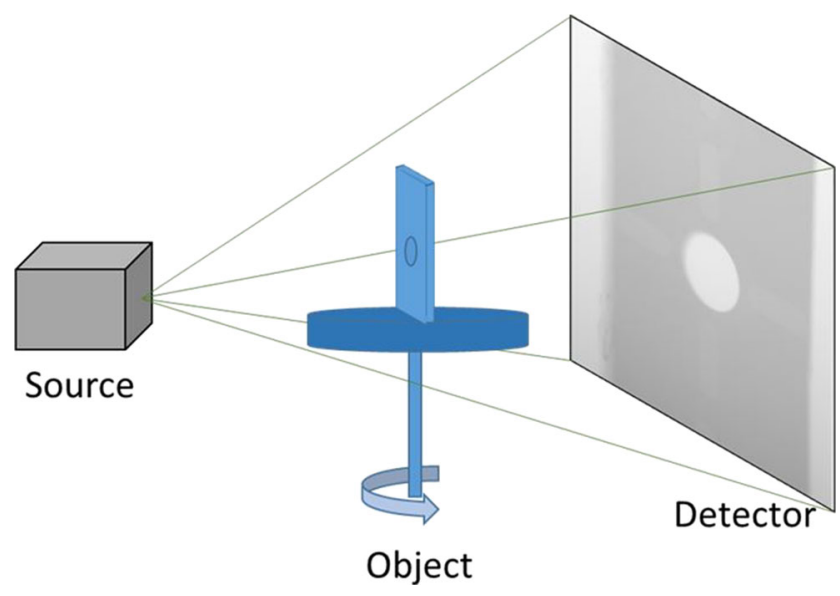

Fig. 1 The grey value of each pixel demonstrates the attenuation level of $\mathrm{x}$-rays from matter

require extensive analysis other than reducing systematic CT errors/artefacts while as a metrological tool, further procedures are required to be followed to overcome and possibly eliminate any issues that can affect the precision of the data. These issues can possibly affect the CT data caused by bi-directional repeatability of the system, radial run-out errors, the detector tilt and type, size and movement of the $\mathrm{x}$-ray spot during the scan. The effect of these issues can be reduced by following the recommendations provided in VDI/VDE 2630 Part 1.4, a guide to obtain dimensional measurements through CT. In order to eliminate absolute scale errors in CT measurements that are caused by imprecise voxel size, nominal/actual comparison between the scanned data and a reference measurement is required according to these guidelines. This comparison can reduce the systematic measurement error from 1 to $0.2 \%$ [1-4, 6-12].

This paper demonstrates a method of CT scanning and analysing multi-material parts that are affected by the limitations of a CT system and they are suffering from beam hardening and noise. In order to develop and demonstrate the capabilities of this method, multi-material samples were examined. The samples are combining carbon fibre reinforced polymers (CFRPs) and titanium alloy which are materials with distinctively different densities.

\subsection{Examined materials}

Composite materials are often favoured over traditional materials for structural applications due to their higher specific properties of strength and stiffness, leading to weight reduction of the entire structure and reduction of energy consumption. For this reason, composites such as CFRPs are increasingly being utilised in aerospace, navel, space and automotive applications. Similarly, titanium and its alloys are often used because of their high strength to weight ratio, compressive and tensile strength at high temperature, low density, corrosion and erosion resistance, fatigue resistance and low modulus of elasticity. These materials are frequently combined by bolting and riveting to optimise the weight to strength ratio $[13,14]$.

Numerous studies examine the drilling of CFRPs as machining difficulties are often encountered. Composite materials are anisotropic, non-homogenous and heat sensitive, while their machining behaviour depends on diverse reinforcement and the properties of their matrix. CFRPs achieve their mechanical and structural properties from the nature, orientation and bond of fibres that are arranged in flat panels, sheets or woven structures [13-21]. Any machining that breaks the fibres influences the properties and service life of the part. Many studies have examined different machining processes, tools, set-ups and settings, and it can be concluded that the formation of defects and high wear of the cutting tools are caused by the nonoptimum combination of process parameters, tool geometry and cutting tool material [13, 22-26].

Wherever possible, composites are produced with near net shape processes to avoid damages caused by machining; however, drilling is a secondary machining process that is difficult to avoid since it is required to install mechanical fasteners. The drilling process can cause fragmentations, burrs, interlaminar cracks, interfacial de-bounding, thermal damages and fibre pull-outs. A high percentage of part rejections are due to poor hole quality [13-19, 22, 27, 28]. The examination of the holes after their production is undertaken by destructive and non-destructive methods, to better understanding the effects of the machining processes and the way that they affect the service life of the part. Different machining processes are continually being studied to improve the outcomes [13, 17-19, 22-28].

The effect of tool characteristics such as geometry, material and type have been considered in several studies with the results indicating that smaller contact length between drill and hole and a smaller chisel size are beneficial. The other important aspects of drilling CFRPs are tool thrust and torque, feed rate and cutting speed. The defects are attributed to the brittle nature of the fibres that are deformed and cut by brittle fracture during machining which often results in uncut fibres and rough surface finish. Tool wear and thrust forces contribute to the formation of defects while low cutting speeds and high feed rate, such as less than $50 \mathrm{~m} / \mathrm{min}$ and more than $0.1 \mathrm{~mm} / \mathrm{rev}$ respectively, cause fibre breakage, pull-outs, cracks and delamination. The machining of CFRPs is also affected by the low temperature strength of the matrix that is typically less than $180{ }^{\circ} \mathrm{C}$ and temperatures higher than this result in material softening, degradation and poor surface finish [29-31].

Titanium is widely used in the aerospace industry, for example, aircraft turbine and compressor blades and discs. Combining CFRPs with metals such as titanium and its 
alloys introduces more challenges due to its higher specific properties, significantly formation and tool wear. Concentrated heat at the cutting edges results from low thermal conductivity of the material. Temperatures can rise to over $1000{ }^{\circ} \mathrm{C}$ in dry conditions resulting in a chemical reaction with the tool material leading to tool weakening and failure, while the titanium maintains its properties of hardness and strength. As a result, the machining of titanium typically incurs high machining cost with high tool wear, tool life is decreased by chipping, and burrs are introduced to both entrance and exit surfaces of the holes. Thrust force, tool wear and the increase of the feed rate during drilling affect the formation and size of burrs, which may result in inaccuracies and assembly errors [14, 32-36].

The results of different drilling methods such as ultrasonic-assisted drilling (UAD) have been compared to conventional drilling (CD) in order to identify optimum setting. The utilisation of UAD in the drilling of CFRP has been shown to improve the quality of the holes, while the results for its application on titanium alloys are more varied, with some studies demonstrating different results for different alloys and others showing benefits with lower thrust forces. It is generally accepted that UAD increases tool life, which affects the quality of the holes, due to less titanium adhesion on the cutting edges and less edge chipping which corresponds to reduced titanium burr [36-39]. The process relies on the application of ultrasonic vibrations of 2-20 $\mu \mathrm{m}$ and $20-45 \mathrm{kHz}$ amplitude and frequency, respectively, which is superimposed in the feed direction of the cutting edges during drilling. The CFRP results of this method demonstrate lower thrust forces, lower surface roughness, smaller delamination and improved circularity compared to $\mathrm{CD}$ [38]. Nevertheless, higher cutting temperatures are observed during UAD of CFRPs and titanium alloys individually which are proportional to the ultrasonic amplitude due to energy consumption as the tool vibrates. Measurements of drilled through stacks of CFRP/Ti6Al4V, produced by UAD and CD with a three-point bore micrometre has shown more consistent and closer to nominal diameters for UAD [37-40]. The application of UAD demonstrates promising results and further investigation is required, while the combination of CFRPs and titanium alloys introduces unforeseen challenges that depend on the nature of the specific combination of CFRP and titanium alloy.

\subsection{Quality inspections and computed tomography}

The investigations of different machining processes and combinations of different materials usually apply destructive methods by cutting the part to examine it. As a result of these examinations, part of the specimen is destroyed and some potentially useful data is lost. Optical inspections with microscopes while non-destructive can only provide data of the entrance and exit surfaces of the drilled holes and surface roughness examinations provide limited data of specific points.

The most common examination methods used in the investigation of defects of CFRPs are radiography, ultrasonics, and eddy-currents after optical examinations and destructive test. Optical techniques used in the past include infra-red thermography while the specimen is under load, eddy currents with special probes, pulse echo ultrasonics, digital image analysis, shadow moire laser and guided waves [18, 22, 41-47]. These methods were used to identify the orientation of fibres, defects and their type, fibre fractions resin-rich zones, impact damages, the extent of hidden delamination and the growth of fatigue damages during tests. Each method has its limitations, and they are chosen according to the application. All of these methods provide limited data with constrained accuracy which is subject to human error, and they are unable to provide data for the entire specimen. The inspection of titanium also includes destructive methods that are then optically examined with microscopes and non-destructive methods such as radiography, ultrasonics and eddy currents with similar limitations as previously discussed [18, 22, 41-47].

The combined issues caused by drilling of these materials require the identification of the optimum machining settings for the specific combination of materials. This study examines and compares drilled holes produced by UAD and CD of CFRPs and titanium alloy Ti6Al4V stack using CT and image processing. The holes examined in this case study are part of an investigation to identify optimum drilling methods and settings that could benefit an industrial production

Table 1 Machines and software used in this method

\begin{tabular}{llll}
\hline Machines and software used & Name & Producer & Year \\
\hline X-ray CT scanner & X-TEK XT H 225/320 LC & Nikon Metrology, UK & \\
Optical CMM scanner & NEXIV VM2 - R6555 & Nikon Metrology, UK & Nikon Metrology, UK \\
CT Reconstruction software & CT Pro 2.4 & Volume Graphics GmbH, Germany \\
CT Inspection software & VG Studio Max 2.2 & MathWorks, USA & 2014 \\
Analysis software & Matlab & & 2014 \\
\hline
\end{tabular}


line. The method used is based on an investigation of CFRP drilled holes utilising CT and image processing [48]. The combination of different materials and the significant difference of their atomic mass and structure introduce issues to the CT examination and image processing analysis that are identified and overcome by this method.

\section{Method}

The method presented here was developed to examine different materials with significantly different atomic mass and structure. A stack of CFRP and Ti6Al4V was used to demonstrate the results of the method. The examined samples are test results of two different machining processes, and they are part of an investigation to identify the optimum drilling settings. The CT examination of the two drilling methods, CD and UAD, can provide information about the quality of the holes and assists in the identification of the optimum settings for this combination of materials. The evaluation of the quality of the holes is based on the internal damage of the materials, the circularity and centre deviation of the entire hole. The image processing analysis is based on a method developed to evaluate the quality of CFRP holes $[5,48]$. All of the scanners and software packages used are provided in Table 1.

\subsection{Preparation of the parts}

Both machining processes, $\mathrm{CD}$ and $\mathrm{UAD}$, were performed on CFRP/Ti6aAl4V stacks with the same machine, Ultrasonic 65 monoBLOCK, DMG with an ultrasonic actuator built into the tool holder, as shown in Fig. 2. The two materials were joined together with Hysol 9492 prior to the machining. The thickness of the different materials was $4 \mathrm{~mm}$. The cutting speed and feed rate were constant at

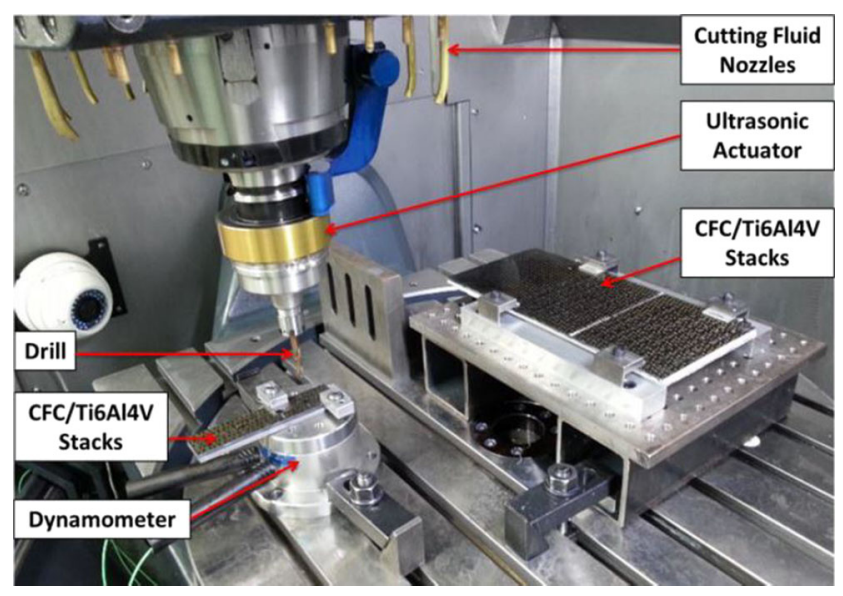

Fig. 2 Experimental drilling set-up of conventional and ultrasonic drilling

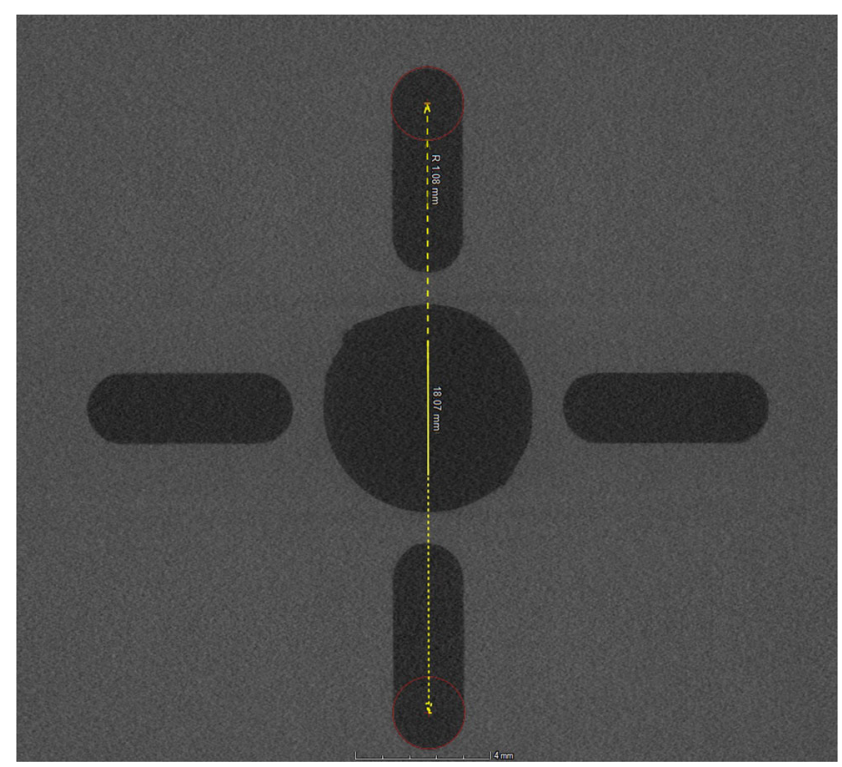

Fig. 3 Voxel rescaling according to CMM measurements. The centre to centre distance of the prescribed circles shown are scaled to the actual canter to centre distance measured by optical CMM

$50 \mathrm{~m} / \mathrm{min}$ and $0.05 \mathrm{~mm} / \mathrm{rev}$, respectively. The drilling took place with a reground tungsten carbide 2-flute twist drill with point angle of $140^{\circ}$ and a helix angle of $30^{\circ}$. The diameter of the tool was $6.12 \mathrm{~mm}$ and 50 holes for each technique were drilled. In order to compare the two techniques and examine the effect of the tool wear into the quality of the results, one hole was examined for every 10 drilled holes, 5 holes per technique. The drilling initiated with CFRP material on the top and as a result the entrance surface is CFRP while the exit surface is Ti6Al4V. The cooling method used for both techniques was via the external

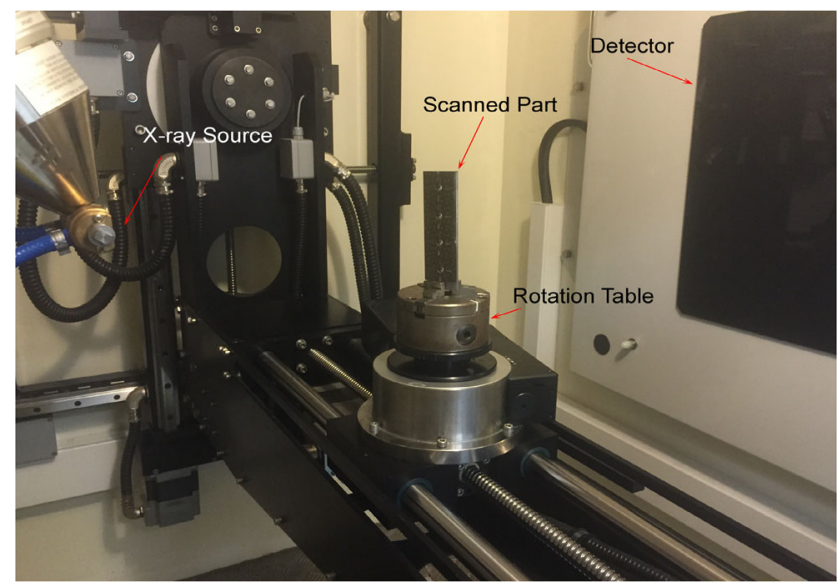

Fig. 4 X-ray set-up. In order to achieve maximum resolution, the part needs to be place as close to the $\mathrm{X}$-ray source as possible while keeping the part in the field of view 
Table 2 Selected CT settings

\begin{tabular}{ll}
\hline CT settings & \\
\hline Voltage $(\mathrm{kV})$ & 215 \\
Power $(\mathrm{W})$ & 6 \\
Exposure Time $(\mathrm{s})$ & 4 \\
Gain $(\mathrm{dB})$ & 18 \\
Voxel size $(\mu \mathrm{m})$ & 17.5 \\
X-ray filtration $(\mathrm{mm})$ & 0.675 \\
X-ray filtration Materia & Tin \\
\hline
\end{tabular}

application of a standard water-based cutting fluid. The UAD holes were produced with maximum oscillation of $2.6 \mu \mathrm{m}$ and the frequency of the vibrations was $42.7 \mathrm{kHz}$. The positioning of each hole according to the manufacturer is $\leq 8 \mu \mathrm{m}$.

Four slots were produced prior to the drilling of each hole so as to mark the centre of the hole and the orientation of the part during the drilling, as shown in Fig. 3, and they were used for voxel rescaling during the image processing. The tool used for the production of the slots was a 2-mm-diameter Q-coat tungsten carbide slot drill with cutting speed $18.833 \mathrm{~m} / \mathrm{s}$, cross feed $0.042 \mathrm{~m} / \mathrm{s}$ and depth feed $0.002 \mathrm{~m} / \mathrm{s}$. Their depth is $0.7 \mathrm{~mm}$ and length $8 \mathrm{~mm}$.

\subsection{CT acquisition and reconstruction}

CT scanning depends on a series of variables that are selected based on the scanned material, the capabilities of the CT system and the required resolution. In order to achieve optimum results that can be used for a metrological investigation, VDI/VDE 2630 Part 1.4 guidelines were followed. The CT scanning set-up is shown in Fig. 4.

Initially, the stacks of CFRP/Ti6Al4V were scanned prior to the drilling to ensure the quality of the joining with Hysol 9492. Then, the part was scanned after the drilling to investigate the quality of the holes. The settings selected are shown in Table 2 and the positioning of the parts was selected for maximum magnification resulting in a voxel size and resolution of $17.5 \mu \mathrm{m}$.

The combination of the two materials with distinctly different atomic masses cause one of the most common CT artefacts, which is beam hardening. Figure 5 demonstrates the effect of beam hardening and noise caused by the scanning of the two materials with the histogram providing the amount of grey values in the length of the red line. The black line in the histogram demonstrates the point where the materials intersect. The areas that are affected by these artefacts are around the titanium alloy. Prior to the reconstruction of the $2 \mathrm{D}$ images, a beam hardening reduction algorithm with offset was used to minimise the effect of the artefacts in the model [49].

After the reconstruction of the images to a 3D model, each hole was aligned based on the slots produced prior to the drilling to the intended centre of the hole. Each slot was measured with optical CMM and the distances between the slots were later used for voxel rescaling performed in VG Studio Max 2.2, as shown in Fig. 3. Each CMM measurement was repeated five times to improve the accuracy and reduce the uncertainty of the results. The voxel rescaling took place prior to the image processing during the alignment of the part according to the slots that demonstrate the indented machining axis. The aligned model was then exported as a 2D DICOM image stack for analysis, where each slice is one voxel thick.

\subsection{Image processing}

The DICOM images were exported by the visualisation software VG Studio Max 2.2 for image analysis in MATLAB. The Otsu method was used to identify the required threshold to convert the grey images to binary and the Hough transform was used to identify the lines of the markings and calculate the ideal centre [50]. The Wiener filter was also used to reduce the noise introduced by the residual beam
Fig. 5 The histogram demonstrates the irregularities of grey values at the red line in the $2 \mathrm{D}$ slice. The black line in the histogram shows the point where the material change
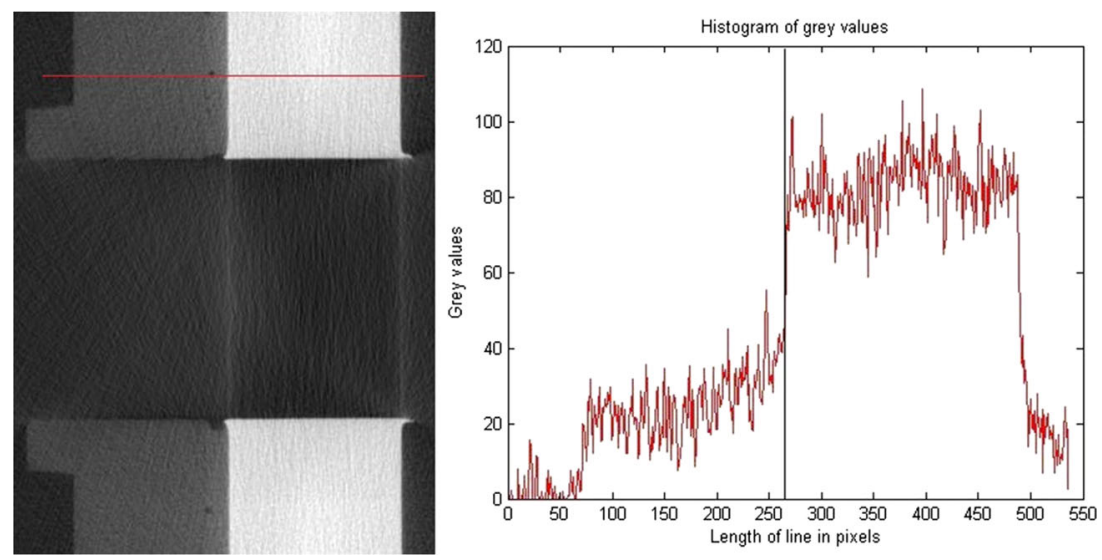


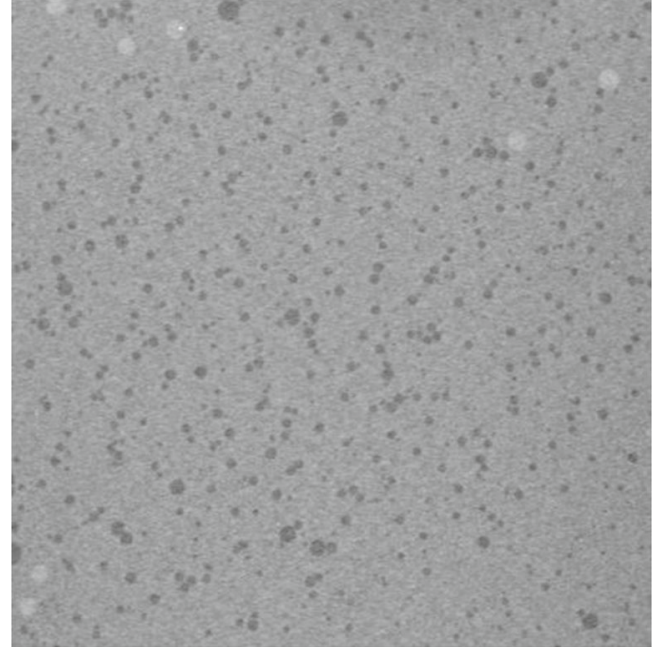

Fig. 6 Examination of the join show extreme porosity. Pores are represented as black and glass particles as white

hardening. It is based on statistical methods to identify and remove noise by considering the neighbourhood of each pixel, removing abhorrent values. Removal of noise in this manner is edge preserving. The Canny method was used to identify the edges that form the circle and a circular Hough transform was used to identify the circles and calculate the actual radius.

Initially, an image close to the entrance surface was selected and the slots were used as markings to identify the ideal centre of the hole. This measure was applied to all images that were used to calculate the maximum and

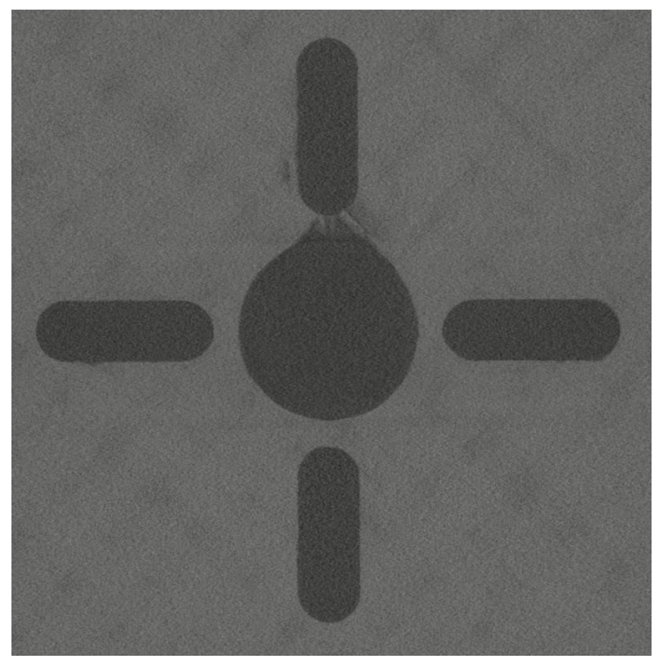

Fig. 7 The slots are close to the hole and may have affected the entrance delamination
Table 3 Tolerances when drilling CFRPs

\begin{tabular}{lll}
\hline Tolerances type & Symbol & Tolerances values (mm) \\
\hline Diameter & $\varnothing$ & $6.120+0.075$ \\
Circularity & $\bigcirc$ & $0+0.200$ \\
Positioning & $\varnothing$ & $0 \pm 0.075$ \\
\hline
\end{tabular}

minimum radius, maximum and minimum diameter, circularity, perimeter and positioning of the circle shown in every slide. The maximum and minimum radii were found by calculating the distance between the ideal centre and the edges of the circle. The maximum and minimum diameters were calculated by two points that intersect the circle edge from the line that passes through the ideal centre. The circularity was calculated as the difference between the maximum and minimum radii which agrees with ASME Y 14.5M 1994 [51]. The circumference of the hole can indicate the extent of delamination instead of the maximum that is identified by the calculations of diameter and radius. However, due to the defect, the shape of the hole can become abstract and as a result it is called perimeter. The perimeter of each hole was calculated by the points of the edge. The positioning of the hole was calculated as the absolute difference between the ideal centre and the actual centre of the circle identified by the actual centre of the circle determined by the circular Hough transform.

\section{Results and discussion}

Initially,the joining of the two materials was visually examined prior to the drilling, as shown in Fig. 6. The joining of the materials was achieved by Hysol 9492 and includes glass particles with $0.3 \mathrm{~mm}$ diameter to ensure homogenous thickness. The results show significant porosity in the join and the glass particles are easily identifiable from their higher density in comparison to the surrounding material. This joining was intended to bond the two materials together after the drilling for the CT investigation since no other fastening method is used.

Each hole was also visually inspected prior to the image analysis to identify any abnormalities. Concerns were raised because it is believed that the close proximity of the slots to hole could had affected the entrance delamination as shown in Fig. 7, subsequent analysis negates the entrance delamination that may have been compromised, although this effect is well known and previously quantified [22, 23, 28]. 
The image analysis provided data on the maximum diameter and radius, the circularity, perimeter and positioning, that were used to compare the two different drilling methods and the effect of the tool wear throughout the drilling of 50 holes. It also demonstrates whether the tolerances are met that determine the quality acceptance or failure of the part. The tolerances provided in Table 3 are an example of typical tolerances required from the aerospace industry for CFRPs [48]. The differences between the two materials are conspicuous with the results improving for the titanium alloy for both drilling methods especially in the latest holes when the tool wear affects the CFRP material greater than

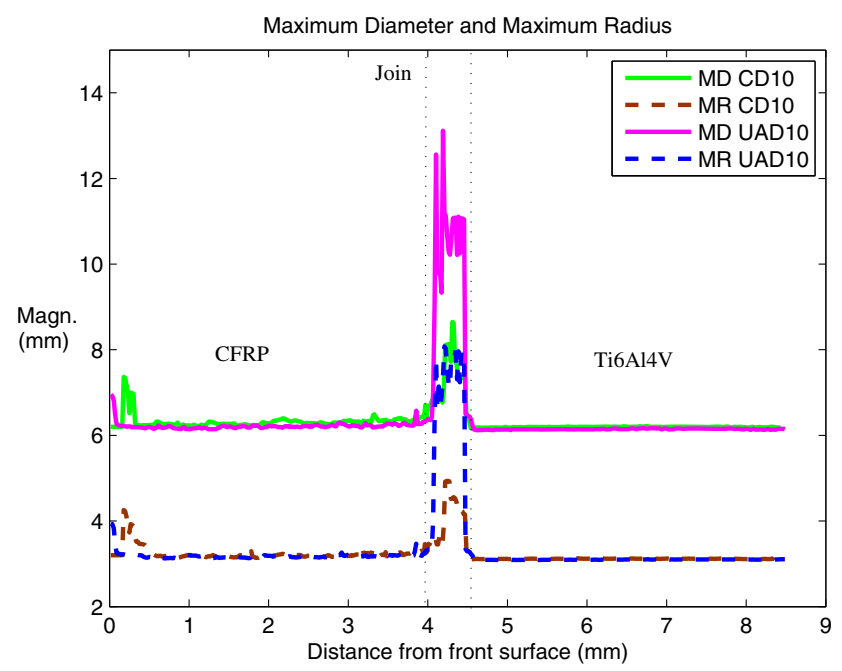

(a)

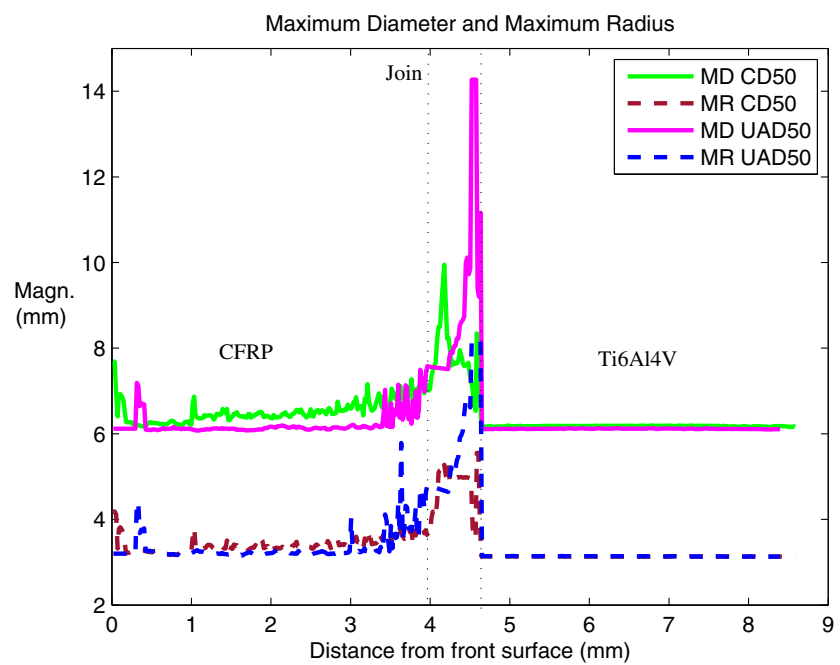

(b)

Fig. 8 Maximum diameter and maximum radius per slide. The different sections of the hole are identified as CFRP, Join and Ti6Al4V. Results for (a) 10th drilled hole and (b) 50th drilled hole
Ti6Al4V. The greatest difference in the results are in the joins that are affected by severe porosity. The results of the maximum diameter and radius of the first and last inspected holes are shown in Fig. 8a, b. Hole nos. 10 and 50 for each technique demonstrate the difference of distribution that is located in the joins due to the porosity and discontinuities of the joining material. In order to examine the results of the two materials better, the following figures do not include the values from the area of the joins.

The results of the first pair of holes, CD10 and UAD10, shown in Fig. 9a indicate that the maximum radius and diameter of both materials are more consistent and closer to tolerance with UAD. The maximum values of maximum diameter and radius for CFRP are 6.432 and $3.365 \mathrm{~mm}$ for $\mathrm{CD}$ and 6.293 and $3.209 \mathrm{~mm}$ for $\mathrm{UAD}$, ignoring the entrance delamination and the joining session, the maximum diameter for the Ti6Al4V is $6.204 \mathrm{~mm}$ for CD and $6.163 \mathrm{~mm}$ for UAD, the maximum radius of Ti6Al4V is stable and does not exceed $3.125 \mathrm{~mm}$. Even so, both holes would have failed inspection since the CFRP part of the holes exceed the required tolerance of $6.195 \mathrm{~mm}$ diameter. Figure $9 \mathrm{~b}$ shows the results of circularity. Overall, the results are similar for the two drilling methods with the Ti6Al4V circularity varied around $0.055 \mathrm{~mm}$ and the CFRP circularity varied just below the tolerance of $0.200 \mathrm{~mm}$ except the few random peaks reaching $0.504 \mathrm{~mm}$ for UAD and $0.207 \mathrm{~mm}$ for $\mathrm{CD}$. The maximum value of circularity for the CFRP is $0.273 \mathrm{~mm}$ for CD and $0.0239 \mathrm{~mm}$ for UAD. The circularity of Ti6Al4V is stable for both drilling methods and it does not exceed $0.080 \mathrm{~mm}$. Perimeter results of the first holes, CD and UAD 10, also indicate that UAD provides slightly more stable results, as shown in Fig. 9c. The difference between the two techniques is not significant and show that the perimeter of the UAD hole does not exceed $26.149 \mathrm{~mm}$ for CFRP and $24.699 \mathrm{~mm}$ for Ti6Al4V while the results of the CD hole demonstrate that the perimeter reaches $27.871 \mathrm{~mm}$ for the CFRP and $24.899 \mathrm{~mm}$ for the Ti6Al4V. The positioning of the holes, shown in Fig. 9d, fail to meet the tolerance target of $0.075 \mathrm{~mm}$ and reaches $0.237 \mathrm{~mm}$ for CD and $0.241 \mathrm{~mm}$ for UAD. The results of both drilling methods give similar readings and CFRP positioning is worse than the positioning of Ti6Al4V.

The results of both materials worsen with tool wear, especially for $\mathrm{CD}$. Figure 10 shows the maximum radius, circularity, perimeter and positioning differentiate the results of the two drilling methods, more for CFRP while the results are getting more similar for the titanium alloy. Figure 10a shows that that UDA hole provides better results since both CFRP and Ti6Al4V are below the tolerance with only a 


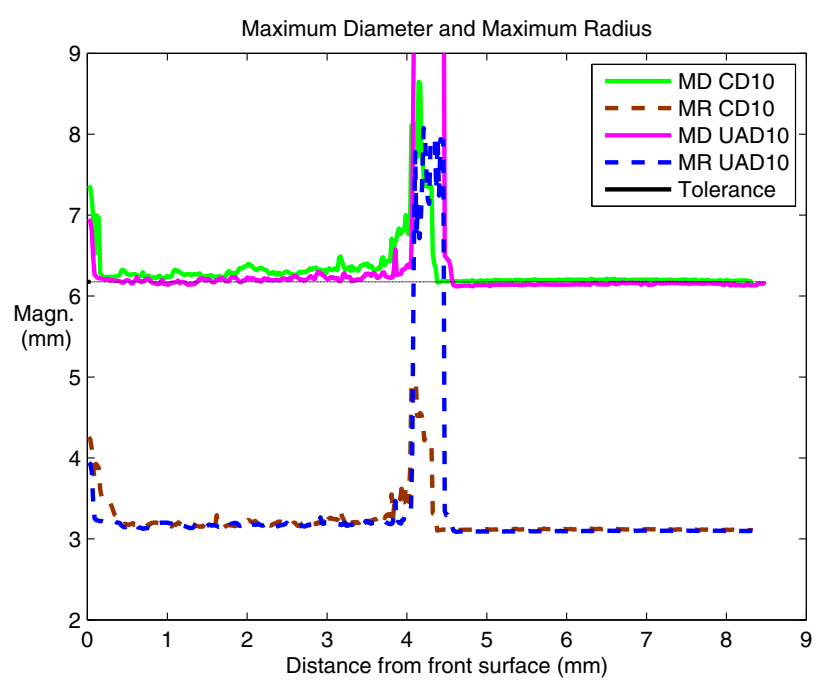

(a)

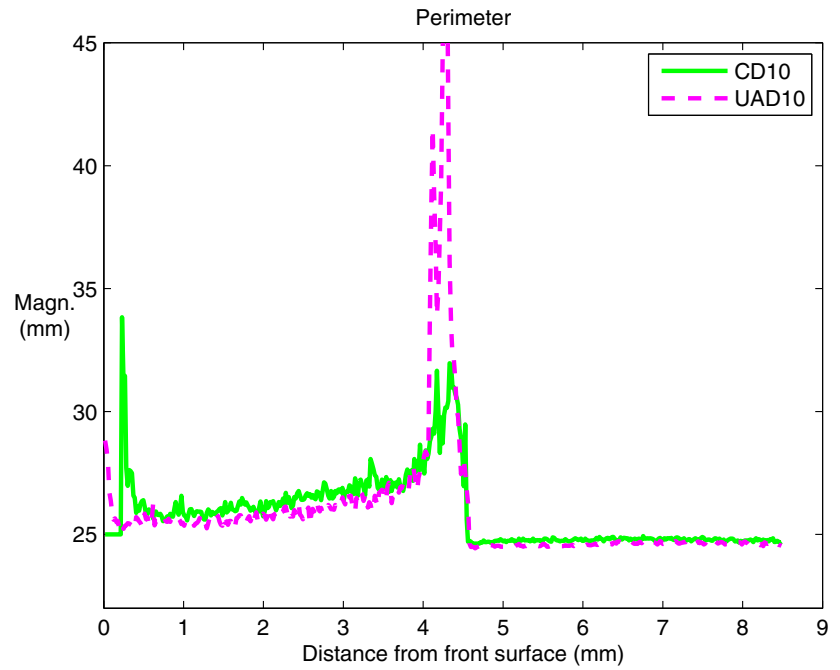

(c)

Fig. 9 The results of the first holes for both $C D$ and UAD of the 10th holes. The results shown are per slice and the entrance surface is located at $0 \mathrm{~mm}$ and exit surface at $8.4 \mathrm{~mm}$. Tolerances are given for diameter, circularity and positioning. Panel a shows the maximum

few high values exceeding for the CFRP and indicate exit delamination with a radius reaching $5.784 \mathrm{~mm}$. Ti6Al4V radius is in the steady range of $3.130 \mathrm{~mm}$. The circularity results shown in Fig. 10b show CFRP results slightly failing to meet the tolerance with few worse exceptions close to the entrance and exit CFRP surfaces reaching $1.407 \mathrm{~mm}$. Ti6Al4V results show a better picture for both drilling techniques with the circularity stable close to $0.098 \mathrm{~mm}$. The

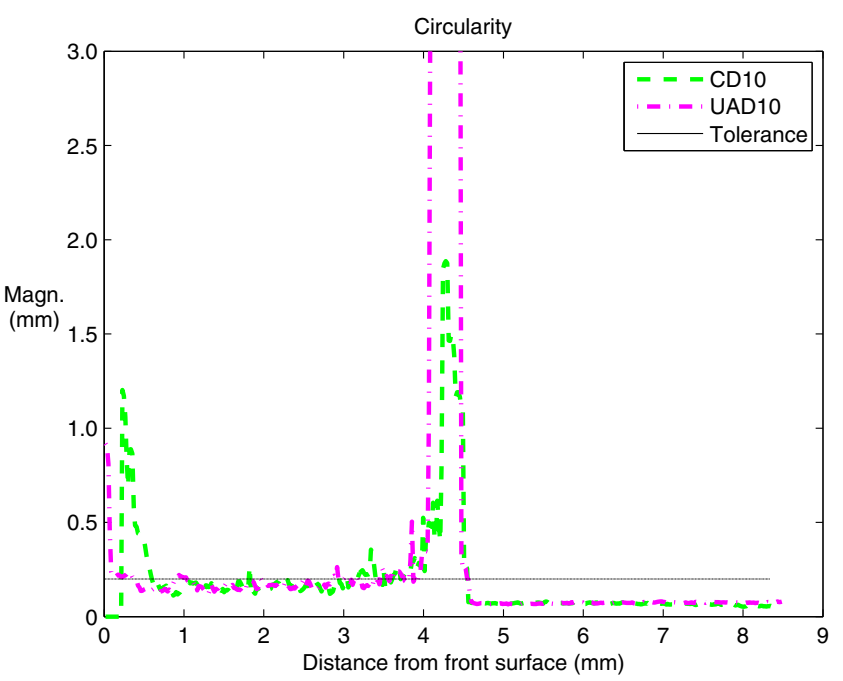

(b)

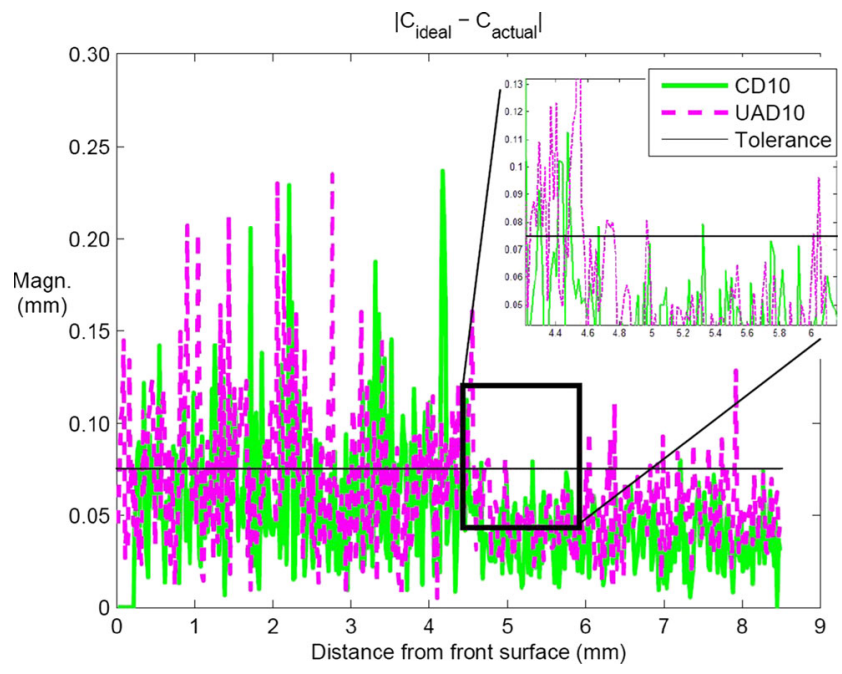

(d)

diameter and radius, $\mathbf{b}$ shows the circularity results, $\mathbf{c}$ show the results for the perimeters and (d) shows the positioning with a zoom in area to demonstrating the difference between the two materials

perimeter results, Fig. 10c, similarly show stable results for Ti6Al4V for both drilling methods while the perimeter of CFRP reaches $33.141 \mathrm{~mm}$ close to the entrance surface for both techniques. The circularity and perimeter results shown in Fig. 10b, c show that tool wear affects CD more than UAD. The results of positioning of the holes, Fig. 10d, show that tool wear affects the position of both $\mathrm{CD}$ and UAD, and reaching $0.3 \mathrm{~mm}$ for CFRP. 


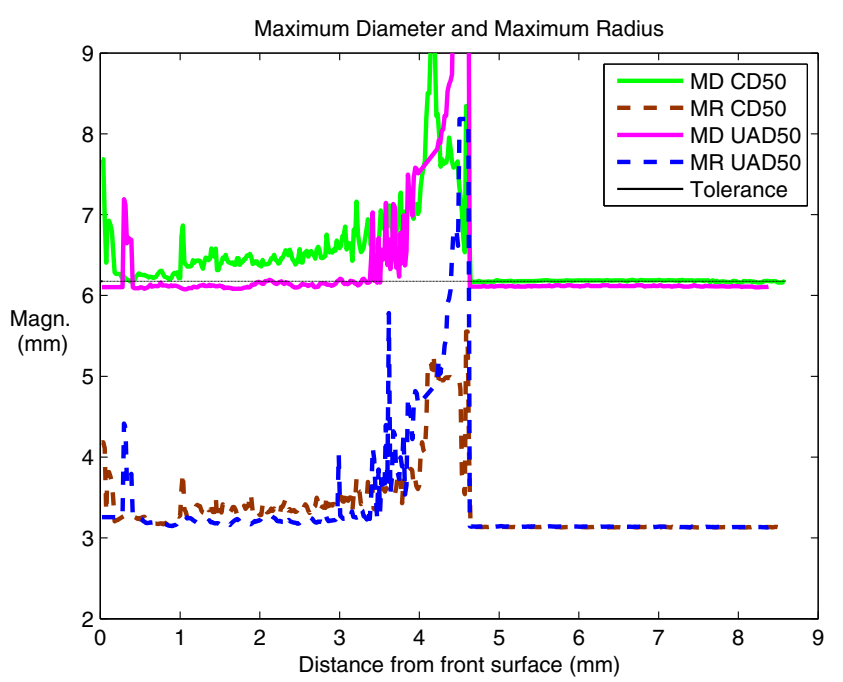

(a)

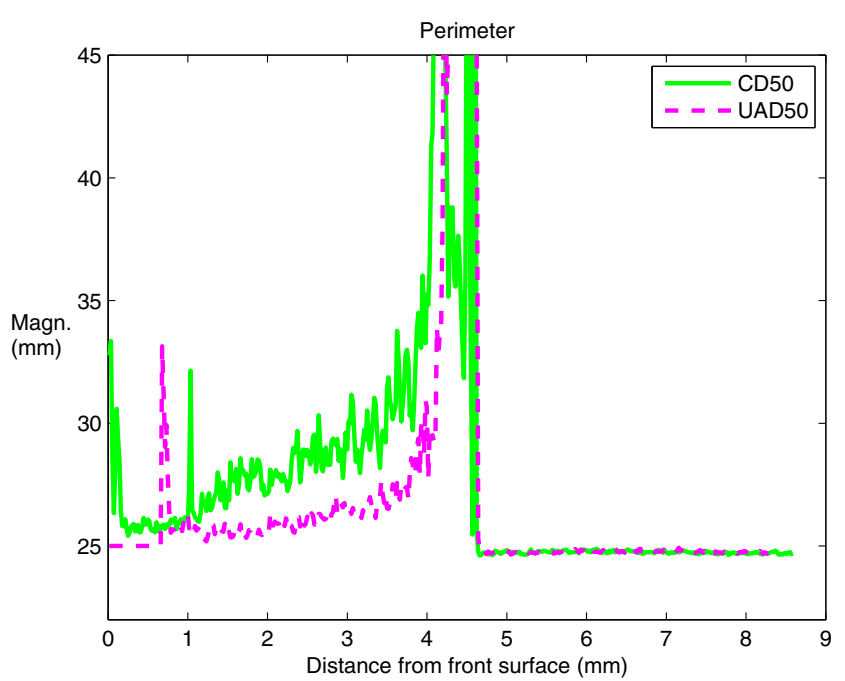

(c)

Fig. 10 The results of the last holes for both $C D$ and UAD of the 50th holes. The results shown are per slice and the entrance surface is located at $0 \mathrm{~mm}$ and exit surface at $8.4 \mathrm{~mm}$. Tolerances are given for diameter, circularity and positioning. Panel a shows

\section{Conclusions}

This paper demonstrates a new method of multi-material CT scans and analysing them with image processing. CT scanning of two or more materials with significantly different atomic mass and structure can cause beam hardening and noise that affects image quality. The method combines physical filtration to reduce the spectrum of polychromatic radiation, alongside beam hardening reduction algorithms

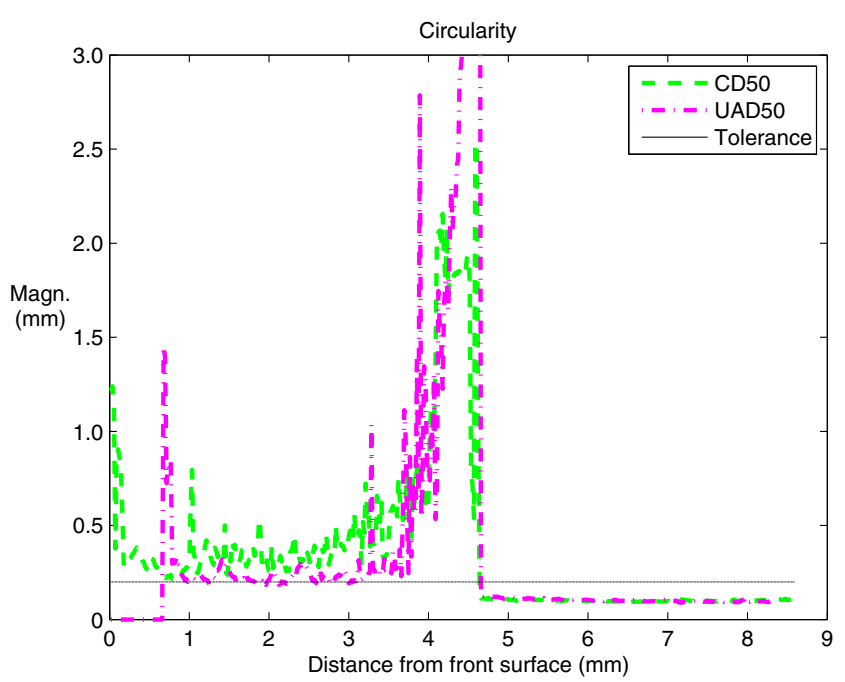

(b)

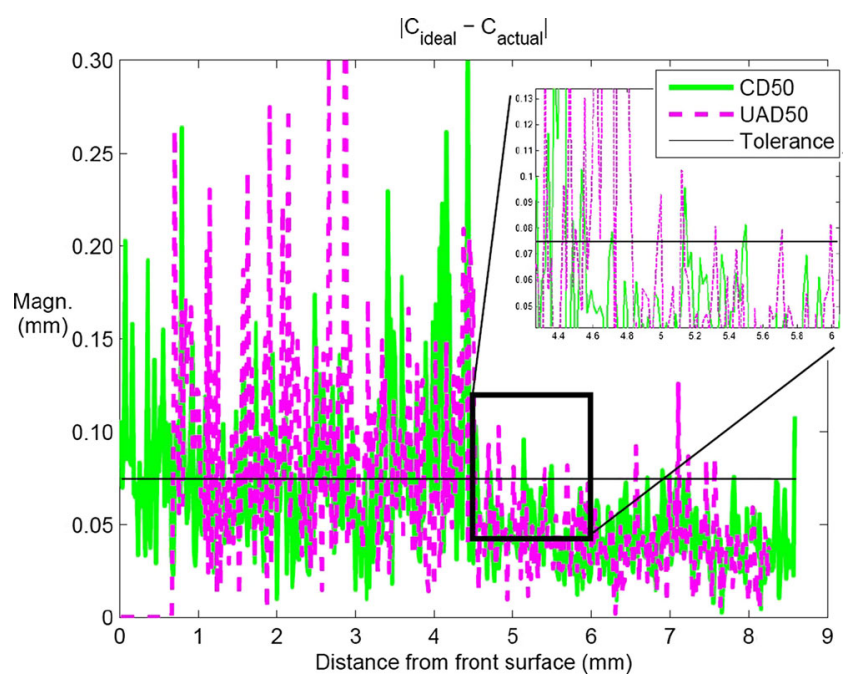

(d)

maximum diameter and radius, $\mathbf{b}$ shows the circularity results, c show the results for the perimeters and (d) shows the positioning with a zoom in area to demonstrating the difference between the two materials

and image processing algorithms to reduce the noise from residual beam hardening. In order to demonstrate the effect of this method, the results of two different drilling methods, $\mathrm{CD}$ and UAD, on a stack of CFRP/Ti6Al4V, were examined. The combination of the two materials introduces challenges to the already difficult machining process since both materials require special consideration with specific settings to be machined. The combination of CT scanning and image processing provides quantitative quality assessment of the 
machining processes that were previously inaccessible with any other non-destructive method.

The parameters considered were maximum diameter and radius, circularity, perimeter and positioning of each hole. The joining of the two materials with Hysol 9492 contained porosity that could adversely affect the drilling process and the resultant hole dimension. The joining method was kept constant between all parts to ensure similar initial conditions as found in initial scans prior to drilling. The results demonstrate that $\mathrm{Ti} 6 \mathrm{Al} 4 \mathrm{~V}$ is more resilient to the drilling process with the aforementioned parameters remaining within tolerance. The CFRP results are within tolerance when using new drills, but the material becomes increasingly prone to defects as the tool begins to wear as shown in later holes. In hole no. 10 where tool wear is at lowest level, the combination of the two materials has minimal exit delamination of the CFRP, while hole for sample no. 50 for both drilling methods demonstrates severe exit delamination and an increase diameter. The results of maximum diameter and radius for both $\mathrm{CD}$ and UAD are similar within Ti6Al4V for all holes. UAD provides slightly better results for CFRP where the positioning of the hole is not affected by the selection of the machining method. The results indicate that the deterioration of the tool affects the quality of the holes, and this hypothesis will be investigated in future works.

This investigation inspected examples of the two drilling methods without identifying the optimum drilling settings. The results provided in this study are not representative of production holes and demonstrate that further investigation is required to identify appropriate methods, settings and setups for drilling sandwich materials. The combination of the two materials increases the tool wear that affects the quality of the holes. In this case study, the tolerances were used for demonstration based on the tolerances followed by the aerospace industry for CFRP drilling only.

Acknowledgments The authors would like to thank BAE Systems and EPSRC for funding this project.

Open Access This article is distributed under the terms of the Creative Commons Attribution 4.0 International License (http:// creativecommons.org/licenses/by/4.0/), which permits unrestricted use, distribution, and reproduction in any medium, provided you give appropriate credit to the original author(s) and the source, provide a link to the Creative Commons license, and indicate if changes were made.

\section{References}

1. Hsieh J (2009) Computed Tomography - Principles, design, artifacts, and recent advances, 2nd ed. SPIE Press, Washington

2. Herman GT (2009) Fundamentals of computed tomography image reconstruction from projections. Springer, London
3. Kruth JP, Bartscher M, Carmignato S, Schmitt R, De ChiffreL, Weckenmann A (2011) Computed tomography for dimensional metrology. CIRP Ann 2011 - Manuf Technol 60:821842

4. Sun W, Brown S, Leach RK (2012) An overview of industrial $\mathrm{X}$-ray computed tomography. Queen's Printer and Controller of HMSO, England

5. Kourra N, Warnett JM, Attridge A, Erchihan K, Gupta A, Barnes S, Williams MA (2015) Metrological study of CFRP drilled holes with x-ray computed tomography. Int J Adv Manuf Technol 78:2025-2035

6. Welkenhuyzen F, Kiekens K, Pierlet M, Dewulf W, Bleys P, Kruth JP, Voet A (2009) Industrial computer tomography for dimensional metrology: Overview of influence factors and improvement strategies. OPTIMESS Conference:2009

7. Kumar J, Attridge A, Wood PKC, Williams MA (2011) Analysis of the effect of cone-beam geometry and test object configuaration on the measurement accuracy of a computed tomography scanner used for dimensional measurement. Meas Sci Technol 22:3510535120

8. Hiller J, Maisl M, Reindl LM (2012) Physical characterization and performance evaluation of an X-ray micro-computed tomography system for dimensional metrology applications. Meas Sci Technol 23:85404-85422

9. Weib D, Lonardoni R, Deffner A, Kuhn C (2012) Geometric image distortion in flat-panel X-ray detectos and its influence on the accuracy of CT-based dimensional measurements, iCT Conference Austria

10. Dewulf W, Kiekens K, Tan Y, Welkenhuyzen F, Kruth JP (2013) Uncertainty determination and quantification for dimensional measurements with industrial computed tomography. CIRP Ann Manuf Technol 62:535-538

11. VDI/VDE (2010) Computed tomography in dimensional measurements. Measurement procedure and comparability VDI/VDE 2630 Part 1:4

12. Lifton JJ, Malcolm AA, McBride JW, Cross KJ (2013) The application of voxel size correction in X-ray Computed Tomography for dimensional metrology, Singapore International NDT Conference \& Exhibition 2013

13. Teti R (2002) Machining of composite materials. CIRP AnnManuf Technol 51:611-634

14. Isbilir O, Ghassemieh E (2013) Comparative study of tool life and hole quality in drilling of CFRP/titanium stack using coated carbide drill. Mach Sci Technol 17:380-409

15. Ramulu M, Branson T, Kim D (2001) A study of the drilling of composite and titanium stacks. Compos Struct 53:67-77

16. Kim D, Ramulu M (2007) Study on the drilling of titanium/graphite hybrid composites. Trans of ASME 129:390-396

17. Grilo TJ, Paulo RMF, Silva CRM, Davim JP (2013) Experimental delamination analyses of CFRPs using different drill geometries. Compos: Part B 45:1344-1350

18. Persson E, Eriksson I, Zackrisson L (1997) Effects of hole machining defects on strength and fatigue life of composite laminates. Compos: Part A 28A:141-151

19. Abrate S, Walton DA (1992) Machining of composite materials Part I: traditional methods. Compos Manuf 3:75-83

20. Li Y, Zhou J, He Y, Hao X (2015) Drilling delamination and thermal damage of carbon nanotube/carbon fiber reinforced epoxy composites processed by microwave curing. Int $\mathrm{J}$ Mach Tool Manuf 97:11-17

21. Liu D, Tang Y, Cong W (2012) A review of mechanical drilling for composite laminates. Compos Struct 94:1265-1279

22. Davim JP, Reis P (2003) Study of delamination in drilling carbon fiber reinforced plastics (CFRP) using design experiments. Compos Struct 59:481-487 
23. Stone R, Krishnamurthy K (1996) A neural network thrust force controller to minimize delamination during drilling of graphite epoxy laminates. Int J Mach Tools Manuf 36:985-1003

24. Gaitonde VN, Karnik SR, Rubio JC, Correia AE, Abrao AM, Davim JP (2008) Analysis of parametric influence on delamination in high speed drilling of carbon fiber reinforced plastic composites. J Mater Process Technol 203:431-438

25. Abrao AM, Faria PE, Rubio JCC, Reis P, Davim JP (2007) Drilling of fiber reinforced plastics: a review. J Mater Process Technol 186:1-7

26. Marques AT, Durao LM, Magalhaes AG, Silva JF, Tavares JMR (2009) Delamination analysis of carbon fibre reinforced laminates: evaluation of a special step drill. Compos Sci Technol 69:2376-2382

27. Makhdum F, Norddin DNP, Roy A, Silberschmidt VV (2012) Ultrasonically assisted drilling of carbon fibre reinforced plastics. Solid State Phenom 188:170-175

28. Tsao CC, Hocheng H (2004) Taguchi analysis of delamination associated with various drill bits in drilling of composite material. Int J Mach Tools Manuf 44:1085-1090

29. Vob R, etal (2015) Evaluation of bore exit quality for fibre reinforced plastics including delamination and uncut fibres CIRP Journal of Manufacturing Science and Technology

30. Hocheng H, Tsao C (2003) Comprehensive analysis of delamination in drilling of composite materials with various drill bits. $\mathrm{J}$ Mater Process Technol 140:335-339

31. Boyle MM, Martin CJ, Neuner JD (2001) Epoxy resins, ASM handbook ohio: ASM international

32. Feldshtein E (2011) The influence of machining conditions on burr shapes when drilling reach-through holes in difficult to cut materials. Advances Manuf Sci Technol 35:75-83

33. Brinksmeier E, Janssen R (2002) Drilling of multi-layer composite materials consisting of carbon fiber reinforced plastics (CFRP), titanium and aluminum alloys. CIRP Ann - Manuf Technol 51:8790

34. Dornfeld DA, Kim JS, Dechow H, Hewson J, Chen LJ (1999) Drilling burr formation in titanium alloy Ti6Al4V. Ann CIRP 48:73-76

35. Kim D, Ramulu M (2004) Drilling process optimization for graphite/bismaleimide-titanium alloy stacks. Compos Struct 63:101-114

36. Zhang PF, Churi NJ, Pei ZJ, Treadwell C (2008) Mechanical drilling processes for titanium alloys: a literature review. Mach Sci Technol 12:417-444

37. Makhdum F, Phadnis V, Roy A, Silberschmidt V (2014) Effect of ultrasonically-assisted drilling on carbon fibre reinforced plastics. J Sound Vib 333:5939-5952
38. Pujana J, Rivero A, Celaya A, Lopezz de Lacalle L (2014) Analysis of ultrasonic asssited drilling of Ti6Al4V. Int J Mach Tools Manuf 49:500-508

39. Phandis V, Makhdum F, Roy A, Silberschmidt V (2012) Experimental and numerical investigations in CFRP laminate, CIRP, 455-459

40. Dahnel AN, Ascroft H, Barnes S, Gloger M (2015) Analysis of tool wear and hole quality during ultrasonic assisted drilling of carbon fibre composite/titanium alloy (Ti6Al4V) stacks. texas, USA ASME International Mechanical Engineering Congress and Exposition

41. Goeje MP, Wapenaar KED (1992) Non-destructive inspection of carbon fibre-reinforced plastics using eddy current methods. Compos 23:147-157

42. Pye CJ, Adams RD (1981) Detection of damage in fibre reinforced plastics using thermal field generated during resonant vibration. NDT Int 14:111-118

43. Mook G, Lange R, Koeser O (2001) Non-destructive characterisation of carbon-fibre-reinforced plastics by means of eddy-currents. Compos Sci Technol 61:865-873

44. Mouritz AP, Townsend C, Shah Khan MZ (2000) Non-destructive detection of fatigue damage in thick composites by pulse-echo ultrasonics. Compos Sci Technol 60:23-32

45. Steinberger R, Valagas Leitao TI, Ladstatter E, Pinter G, Billinger W, Lang RW (2006) Infrared thermographic techniques for nondestructive damage characterization of carbon fibre reinforced polymers during tensile fatigue testing. Int J Fatigue 28:1340-1347

46. Seif MA, Khashaba UA, Rojas-Oviedo R (2007) Measuring delamination in carbon/epoxy composites using a shadow moire laser based imaging technique. Compos Struct 79:113-118

47. Raisutis R, Kazys R, Zukauskas E, Mazeika L, Vladisauskas A (2010) Application of ultrasonic guided waves for non-destructive testing of defective CFRP rods with multiple delaminations. NDT \& E Int 43:416-424

48. Kourra N, Williams MA, Attridge A, Warnett J, Barnes S, Gupta A (2014) Analysis of drilled holes on carbon fibre material with X-ray Computed Tomography, IEEE International Workshop on Metrology for Aerospace 2014

49. Kachelrieb M, Soubelle K, Kalender WA (2006) Empirical cupping correction: a first-order raw data precorrection for cone-beam computed tomography. Med Phys 33:1269-1274

50. Silva D, Teixera JP, Machado CM (2014) Methodology analysis for evaluation of drilling-induced damage in composites. Int $\mathrm{J}$ Manuf Technol Manag 71:1919-1928

51. Krulikowski A (1997) Form Controls Fundamentals of Geometric Dimensioning \& Tolerancing, vol 71-110. Effective Training Inc, Wayne 